\title{
High Blood Ammonia Levels Associated with Long-term Valproic Acids Therapy in Epileptic Children
}

\author{
I Gusti Lanang Sidiartha, I Gusti Ngurah Made Suwarba, Dyah Kanya Wati, Ida Bagus Subanada \\ Child Health Department, Faculty of Medicine, Udayana University/Sanglah General Hospital, Bali, Indonesia
}

Background: Valproic acid is an effective drug for controlling seizure in children with epilepsy and it is usually used for treatment as long as two years or more. Blood ammonia level often increased in epileptic children who were treated with long-term valproic acid. The study was conducted to determine the relationship between blood ammonia level with valproic acid therapy in epileptic children.

Materials and Methods: This is an observational study with cross-sectional approach. The subjects were 64 children with epilepsy, average age of 6.2 years old. Subjects were 33 boys and 31 girls. Blood ammonia level was examined using enzymatic glutamate dehydrogenase. Subjects were divided into 2 therapeutic groups based on the duration, doses and combination therapy of valproic acid. Subjects were recruited from Pediatric Neurology Clinic, Sanglah General Hospital, Bali, Indonesia, from May to December 2017. Comparison of blood ammonia level between groups were analyzed using an Independent t-test with significances if the $p<0.05$.

Results: A significant difference of blood ammonia level was found between subjects who were treated with valproic acid less than 2 years and more than 2 years $(45.7 \pm 16.4 \mu \mathrm{mol} / \mathrm{L}$ vs. $70.9 \pm 43.6 \mu \mathrm{mol} / \mathrm{L} ; p=0.032)$. However, significant difference was not found between the groups according to the doses and combination therapy ( $p=0.450$ and $p=0.647$, respectively). Conclusion: Blood ammonia level was significantly higher in epileptic children who used long-term valproic acid, hence it was recommended to check the blood ammonia level routinely.

Keywords: ammonia, epilepsy, valproic, children

\section{Introduction}

As an anti-epileptic drug (AED), valproic acid (VPA) is widely used in treatment of seizure in children. However, although VPA is highly effective in controlling seizure in children, it also has several adverse effects such as fatigue, gastrointestinal disturbances, weight gain, muscle tremors, hair loss, thrombocytopenia, and an increase in hepatic enzymes. ${ }^{1,2}$ Other than that, VPA also increases blood ammonia concentrations (hyperammonemia) in adults ${ }^{3-7}$ and children ${ }^{8-15}$. The actual increases in blood ammonia concentrations depend on the dose of VPA ${ }^{4,8}$ and the use of long-term therapy with VPA ${ }^{5}$.

Several studies have reported the relationship between blood ammonia concentrations and VPA therapy. The increase of blood ammonia concentrations is depend

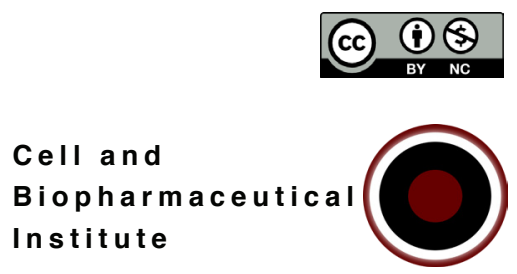

Corresponding Author:

I Gusti Lanang Sidiartha

Child Health Department, Faculty of Medicine

Udayana University

Jl. P.B. Sudirman, Denpasar, Bali, Indonesia

e-mail: lanangsidiartha@yahoo.com

nstitute 
on the dose and duration of VPA and combination therapy with phenytoin, phenobarbital or topiramate, as well as with female gender. ${ }^{4,8}$ The mechanism of hyperammonemia directly inhibits carbamoyl phosphate synthetase (CPS), an enzyme that cause imbalances between the synthesis and degradation of ammonia in the liver and indirectly inhibits the fatty acid beta-oxidation pathway. ${ }^{4}$ Ammonia is toxic, especially to the central nervous system. An increased level of ammonia in the blood is linked with encephalopathy and a worsening of the prognosis for epilepsy.

The study investigated the relationship between blood ammonia concentrations with valproic acid therapy, including duration, doses, and combination therapy. Those variables adjusted on some specific factors as confounding variables such as age, gender, body mass index, and duration of epilepsy.

\section{Materials and methods}

A cross-sectional study was carried out with 64 sample of children with epilepsy who were treated with VPA or VPA and other AEDs for more than 3 months. Children were excluded if they were suffering from metabolic diseases, were receiving therapeutic drugs including salicylate, and/ or undergoing chemotherapy for more than a week, and having high levels of glutamic oxaloacetic transaminase (GOT)/glutamic pyruvic transaminase (GPT) and blood urea nitrogen (BUN)/serum creatinine (SC). The GOT/GPT and $\mathrm{BUN} / \mathrm{SC}$ levels were considered high if it was $>4$ times of range normal, while the normal GOT level=11.0-33.0 $\mathrm{U} / \mathrm{L}$; normal GPT level=11.0-50.0 U/L; normal BUN level=8.0-23.0 mg/dL; normal SC level=0.70-1.20 mg/dL.

The study was conducted at the Pediatric Neurologic Clinic, Sanglah General Hospital, Denpasar, Bali, Indonesia, over an 8-months period from May to December 2017. The Ethical Committee of the Medical Faculty, Udayana University/Sanglah General Hospital, granted ethical approval with No. 2017/UN.14.2/KEP/2017.

Data were collected through anamnesis, physical examination, and medical record, and blood specimen were drawn to check the concentration of GOT/GPT, BUN/SC, and blood ammonia levels. Blood ammonia examination uses enzymatic glutamate dehydrogenase (Cobas Integra, Roche, Basel, Switzerland). After the data were collected, the subjects were divided into 2 groups based on the duration they had been receiving VPA therapy ( $\geq 2$ years and $<2$ years), VPA doses $(\geq 30 \mathrm{mg} / \mathrm{kg} /$ day and $<30 \mathrm{mg} /$ $\mathrm{kg}$ /day), and type of VPA therapy (either it was single drug and multiple drugs or VPA only and VPA + other AEDs), respectively. Subject's blood ammonia concentrations were then compared between the groups.

The sample size calculation was according to formula with $\alpha=0.05$ power $=80 \%$ and clinical difference of blood ammonia level $10 \mu \mathrm{mol} / \mathrm{L}$. The achieved minimal sample size was 64.5. Normality of the numerical data was tested using Kolmogorov-Smirnov and presented as a mean and standard deviation (SD). The differences between the groups were tested using an Independent-t test, and multivariate analysis using $\mathrm{ANCOVA}^{7}$. The data was considered statistically significant if the $p<0.05$.

\section{Results}

There were 74 children with epilepsy treated with VPA during the period of this study. Sixty-four subjects were included in this study after fulfilled the exclusion and inclusion criteria. Of these 64, 33 were male (51.6\%) and 31 female (48.4\%) with a mean age of 6.2 years old. Subjects mean duration of an epilepsy diagnosis was 3.1 years and their mean duration of treatment with VPA was 2.4 years. Table 1 illustratesthe breakdown of subjects overall characteristics.

Table 1. Characteristics of subjects $(n=64)$.

\begin{tabular}{lc}
\hline \multicolumn{1}{c}{ Characteristic } & Mean (SD) \\
\hline Age (years old) & $6.2(3.3)$ \\
Body weight $(\mathrm{kg})$ & $25.1(14.3)$ \\
Body height $(\mathrm{cm})$ & $115.7(21.0)$ \\
Body mass index $\left(\mathrm{kg} / \mathrm{m}^{2}\right)$ & $17.0(3.8)$ \\
Duration of epilepsy (years) & $3.1(2.5)$ \\
Duration of VPA (years) & $2.4(1.9)$ \\
VPA doses (mg/kg/day) & $24.7(3.6)$ \\
Blood ammonia levels $(\mu \mathrm{mol} / \mathrm{L})$ & $53.8(30.2)$ \\
\hline \multicolumn{2}{c}{ Characteristic } \\
\hline Gender & $\mathbf{n}(\mathbf{\%})$ \\
$\quad$ Male & $33(51.6)$ \\
Female & $31(48.4)$ \\
\hline AED therapy & $10(15.6)$ \\
Single & $54(84.4)$ \\
Multiple &
\end{tabular}


Table 2. Bivariate analysis of blood ammonia levels between groups.

\begin{tabular}{|c|c|c|c|c|}
\hline Variable & $\begin{array}{c}\text { Mean }(\mathrm{SD}) \\
\text { Blood Ammonia }(\mu \mathrm{mol} / \mathrm{L})\end{array}$ & Mean Difference & $\begin{array}{l}\text { 95\% Confidence } \\
\text { Iinterval }\end{array}$ & $p$-value * \\
\hline \multicolumn{5}{|l|}{ VPA duration } \\
\hline$\geq 2$ years & $70.9(43.6)$ & 25.2 & $2.3 ; 48.1$ & 0.032 \\
\hline$<2$ years & $45.7(16.4)$ & & & \\
\hline \multicolumn{5}{|l|}{ VPA doses } \\
\hline$\geq 30 \mathrm{mg} / \mathrm{kg}$ & $63.3(18.9)$ & 11.4 & $-19.1 ; 41.9$ & 0.450 \\
\hline$<30 \mathrm{mg} / \mathrm{kg}$ & $51.9(31.9)$ & & & \\
\hline \multicolumn{5}{|l|}{ Combined therapy } \\
\hline Yes & $66.1(29.8)$ & 14.8 & $-67.6 ; 97.2$ & 0.647 \\
\hline No & $51.3(3.6)$ & & & \\
\hline
\end{tabular}

*Independent t-test.

A blood ammonia concentration of more than 60 $\mu \mathrm{mol} / \mathrm{L}$ is classified as hyperammonemia, in this study, 22 subjects (34.4\%) exhibited hyperammonemia. The mean differences in blood ammonia concentrations between the groups according to the duration of VPA therapy, doses of VPA, and combination therapy was analyzed using an Independent $\mathrm{t}$-test and is presented in Table 2.

Multivariate analysis using ANCOVA was done to adjust several confounding variable, such as age and gender. The result of the ANCOVA analysis was still significant for the duration of VPA therapy ( $p=0.042$ ), but not for the VPA doses $(p=0.149)$ and combined therapy $(p=0.186)$ as presented in Table 3.

\section{Discussion}

This study found the blood ammonia concentrations in children with epilepsy were $53.8 \mu \mathrm{mol} / \mathrm{L}$. However, other studies reported different results. They reported that blood ammonia concentrations in children with epilepsy were $46.5 \mu \mathrm{mol} / \mathrm{L}$ and $50.9 \mu \mathrm{mol} / \mathrm{L}$, respectively. ${ }^{8,9}$ Their results were lower than those found in the present study. It may be related with the aged of the subjects.

In the present study, the subject's mean aged were 6.2 years while in the other two studies cited above, they were 7.1 years and 9.2 years, respectively. ${ }^{8,9}$ Thus, the lower mean aged in the subjects of the present study means that

Table 3. Analysis of covariance of subjects' blood ammonia.

\begin{tabular}{lccc}
\hline \multicolumn{1}{c}{ Variable } & $\begin{array}{c}\text { Type III } \\
\text { Sum of Squares }\end{array}$ & F & $\boldsymbol{p}$-value \\
\hline Duration of epilepsy & 17.979 & 0.136 & 0.719 \\
Body mass index & 345.868 & 2.607 & 0.130 \\
Age & 6.876 & 0.052 & 0.823 \\
Gender & 6279.656 & 47.33 & 0.001 \\
VPA duration & 675.093 & 5.088 & 0.042 \\
VPA doses & 312.300 & 2.354 & 0.149 \\
Combined therapy & 258.944 & 1.952 & 0.186 \\
\hline
\end{tabular}


they were likely to exhibit higher concentrations of blood ammonia. ${ }^{9}$

The blood ammonia concentrations of the subjects who receiving VPA therapy for two years or more were significantly higher than those of subjects who receiving VPA therapy for less than two years. The blood ammonia concentrations of each group were $70.9 \mu \mathrm{mol} / \mathrm{L}$ and 45.7 $\mu \mathrm{mol} / \mathrm{L}$ respectively with a mean difference of $25.2 \mu \mathrm{mol} / \mathrm{L}$. Studies on adults with epilepsy reported that the duration of VPA therapy had no significant associations with higher blood ammonia concentration. ${ }^{4}$ Blood ammonia concentration more closely correlated with VPA doses and blood VPA concentration.

In the present study, subjects receiving doses of VPA were divided into two groups: (1) those on $30 \mathrm{mg} / \mathrm{kg} / \mathrm{day}$, and (2) those on less than $30 \mathrm{mg} / \mathrm{kg} /$ day. The first group tends to have higher blood ammonia concentrations than the second $(63.3 \mu \mathrm{mol} / \mathrm{L}$ vs. $51.9 \mu \mathrm{mol} / \mathrm{L})$, respectively, although this was not statistically significant. Other studies reported that blood ammonia concentrations had a positive correlation with the dose of VPA. Higher doses of VPA will result in higher blood ammonia concentrations. ${ }^{8,9}$ The blood ammonia concentrations of children with epilepsy who received VPA therapy with doses of $<10 \mathrm{mg} / \mathrm{kg}, 10$ $20 \mathrm{mg} / \mathrm{kg}, 20-30 \mathrm{mg} / \mathrm{kg}$ and $>30 \mathrm{mg} / \mathrm{kg}$ were $46.8 \mu \mathrm{g} / \mathrm{dL}$, $60.4 \mu \mathrm{g} / \mathrm{dL} 85.7 \mu \mathrm{g} / \mathrm{dL}$ and $92.6 \mu \mathrm{g} / \mathrm{dL}$, respectively. ${ }^{8}$ The dose of VPA apparently appeared to be correlated with blood ammonia concentration in children with epilepsy was $30.4 \mathrm{mg} / \mathrm{kg}$ or more. ${ }^{9}$ Studies in adults also reported that VPA dose was an independent risk factor of blood ammonia concentration. ${ }^{4}$

Another variable that was analyzed in this study was the combination therapy (multi-drug approaches) using VPA in combination with other AEDs. Subjects who received multi-drug treatments (VPA and others AEDs) showed higher levels of blood ammonia compared with those received single drug treatment (VPA only) at 66.1 $\mu \mathrm{mol} / \mathrm{L}$ and $51.3 \mu \mathrm{mol} / \mathrm{L}$, respectively, although this was not statistically significant. However, the other study found a significantly higher of blood ammonia concentrations in subjects who received combination therapy of VPA and other AEDs, particularly phenytoin and phenobarbital. ${ }^{8}$ Studies in adults also reported that combination therapy, particularly liver enzyme-inducing AEDs such as carbamazepine, phenytoin and phenobarbital, resulted in significantly higher concentration of blood ammonia. ${ }^{4}$
One interesting result of the present study was the interaction between the duration of VPA therapy, multidrug therapy, and male gender on the basis of multivariate analysis. Male subjects who received multi-drug therapy for 2 years or more showed significantly higher blood ammonia concentrations than their counterparts. This means that routine blood ammonia monitoring should be carried out with all epilepsy children who have been receiving VPA for 2 years or more, especially in males who have been received combination therapies consisting of VPA and other AEDs.

Another key result was the prevalence of hyperammonemia detected. A diagnostic criterion for hyperammonemia varies between studies. One study used a cut off $40 \mu \mathrm{mol} / \mathrm{L}$ and another $60 \mu \mathrm{mol} / \mathrm{L}$ The study using a cut of $60 \mu \mathrm{mol} / \mathrm{L}$ and found the prevalence of hyperammonemia was $34.4 \%$ while other studies have reported that the prevalence of hyperammonemia varied between $31.7 \%$ and $50 \%{ }^{8,9}$

Epileptic children with VPA at levels exceeded $30.4 \mathrm{mg} / \mathrm{kg} /$ day tend to show a higher prevalence of hyperammonemia. Ammonia, produced as a byproduct of protein metabolism, should be converted to urea in the liver, via the urea-cycle pathway and then excreted in the kidneys. Metabolites of VPA such as valpronyl-coenzyme A propionate and 2-n-propyl-4-pentanoic acid (4-en-VPA) can inhibit the activity of enzymes in the urea-cycle pathway causing hyperammonemia. Ammonia is toxic, especially to the central nervous system, and therefore, increased blood ammonia concentrations in children with epilepsy should be prevented to improve the prognosis of epilepsy.

\section{Conclusion}

Increased blood ammonia concentrations in children with epilepsy who received VPA therapy was prevalent. Routine blood ammonia monitoring is needed, especially in children with epilepsy who have been receiving VPA therapy for more than 2 years. Particular attention should be given in male children with epilepsy who have been receiving multidrug therapy (VPA combined with other AEDs).

\section{Acknowledgements}

Many thanks for the participant of this study, as well to the nursing and medical staff at the Pediatric Neurology Clinic and the Laboratory Department at Sanglah General Hospital for measuring and collecting the data. 


\section{References}

1. Trinka E, Hofler J, Zerbs A, Brigo F. Efficacy and safety of intravenous valproate for status epilepticus: a systematic review. CNS Drugs. 2014; 28(7): 623-39.

2. Nasreddine W, Beydoun A. Valproate-induced thrombocytopenia: aprospective monotherapy study. Epilepsia. 2008; 49(3): 438-45.

3. Wadzinski J, Franks R, Roane D, Bayard M. Valproate-associated hyperammonemic encephalopathy. J Am Board Fam Med. 2007: 20(5): 499-502.

4. Tseng YL, Huang CR, Lin CH, Lu YT, Lu CH, Chen NC, et al. Risk factors of hyperammonemia in patients with epilepsy under valproic acid therapy. Medicine. 2014; 93(11): e66. doi: 10.1097/ MD.0000000000000066.

5. Dahlan MS. Besar Sampel dan Cara Pengambilan Sampel. 2nd edition. Jakarta: Salemba Medika; 2013.

6. Aiyer R, Seide M, Stern RG. Valproic acid induced hyperammonemia in a long time treated patient. Case Rep Psychiatry. 2016; 2016: 6242314. doi: $10.1155 / 2016 / 6242314$

7. Dahlan MS. Statistik untuk Kedokteran dan Kesehatan. 6th edition. Jakarta: Epidemiologi Indonesia; 2014.

8. Agarwal R, Sharma S, Chhillar N, Bala K, Singh N, Tripathi CB. Hyperammonemia and hepatic status during valproate therapy. Indian J Clin Biochem. 2009; 24(4): 366-9.

9. Vazquez M, Fagiolino P, Maldonado C, Olmos I, Ibarra M,
Alvariza S, et al. Hyperammonemia associated with valproic acid concentrations. BioMed Res Int. 2014; 2014: 217269. doi: 10.1155/2014/217269.

10. Yamamoto Y, Takahashi Y, Imai K, Mishima N, Yazawa R, Inoue K, et al. Risk factors for hyperammonemia in pediatric patients with epilepsy. Epilepsia. 2013; 54(6): 983-9.

11. Itoh H, Suzuki Y, Fujisaki K, Sato Y, Takeyama M. Correlation between plasma ammonia level and serum trough concentration of free valproic acid in patients with epilepsy. Biol Pharm Bull. 2012; 35(6): 971-4.

12. Weise S, Syrbe S, Preuss M, Bertsche A, Merkenschiager A, Bernhard MK. Pronounced reversible hyperammonemic encephalopathy associated with combined valproate-topiramate therapy in a 7-yearold girl. SpringerPlus. 2015; 4: 276-9.

13. Nguyen H, Kitzmiller JP, Osuagwu F, Chandran V, Khungar P. Valproate acid (depakote) induced hyperammonemic encephalopathy in the pediatric populations. J Pediatr Neurol Disord. 2017; 3(1): 1-3.

14. Mehndiratta MM, Mehndiratta P, Phul P, Garg S. Valproate induced non hepatic hyperammonemic encephalopathy (VNHE) - a study from tertiary care referral university hospital, North India. J Pak Med Assoc. 2008; 58(11): 627-31.

15. Amanat S, Shahbaz N, Hassan Y. Valproic acid induced hyperammonemic encephalopathy. J Pak Med Assoc. 2013: 63(1): $72-5$. 